\title{
The Authoritarian Dynamic During the COVID-I 9 Pandemic: Effects on Nationalism and Anti-Immigrant Sentiment
}

Social Psychological and

Personality Science

I-I2

(C) The Author(s) 2021

(c) (i)

Article reuse guidelines: sagepub.com/journals-permissions DOI: 10.1 I 177// 948550620978023 journals.sagepub.com/home/spp

(S)AGE

\author{
Todd K. Hartman' ${ }^{\oplus}$, Thomas V. A. Stocks', Ryan McKay², Jilly Gibson-Miller', \\ Liat Levita', Anton P. Martinez', Liam Mason ${ }^{3}$, Orla McBride ${ }^{4}$, Jamie Murphy', \\ Mark Shevlin ${ }^{4}$, Kate M. Bennett ${ }^{5}$, Philip Hyland ${ }^{6}$, Thanos Karatzias ${ }^{7}$, \\ Frédérique Vallières ${ }^{8}$, and Richard $P$. Bentall ${ }^{1}$
}

\begin{abstract}
Research has demonstrated that situational factors such as perceived threats to the social order activate latent authoritarianism. The deadly COVID-19 pandemic presents a rare opportunity to test whether existential threat stemming from an indiscriminate virus moderates the relationship between authoritarianism and political attitudes toward the nation and out-groups. Using data from two large nationally representative samples of adults in the United Kingdom $(N=2,025)$ and Republic of Ireland $(N=I, 04 \mathrm{I})$ collected during the initial phases of strict lockdown measures in both countries, we find that the associations between right-wing authoritarianism (RWA) and (I) nationalism and (2) anti-immigrant attitudes are conditional on levels of perceived threat. As anxiety about the COVID-19 pandemic increases, so too does the effect of RWA on those political outcomes. Thus, it appears that existential threats to humanity from the COVID-19 pandemic moderate expressions of authoritarianism in society.
\end{abstract}

\section{Keywords}

COVID-19, authoritarianism, threat, nationalism, immigration, pandemic, social dominance orientation

Scholars have long argued that perceptions of in-group threat are central to the "authoritarian personality" (Adorno et al., 2019; Altemeyer, 1981; Duckitt, 2001; Feldman \& Stenner, 1997; Sales, 1972). Much of this research focuses on how out-groups pose what scholars label "normative" threats to the social order (i.e., threats to the values, traditions, and social diversity of the in-group) or economic threats to material resources. For example, several studies demonstrate that perceived threat related to economic competition (Rickert, 1998), security and stability in society (Roccato \& Russo, 2017; Roccato et al., 2014), and social cohesion (Stenner, 2005) moderates the association between right-wing authoritarianism (RWA) and prejudicial attitudes. However, other scholars argue that we should also consider how threats to one's very existence (e.g., the 9/11 terrorist attacks) interact with authoritarianism (Cohrs et al., 2005; Kossowska et al., 2011; Lavine et al., 2002, 2005; cf. Hetherington \& Suhay, 2011). In fact, some researchers find that existential threats stemming from terrorism have larger effect sizes on political attitudes and behaviors than we might find from economic threats (e.g., see Merolla \& Zechmeister, 2009).

The COVID-19 pandemic, which has already killed more than a million people worldwide, offers us a rare opportunity to test whether existential threat stemming from a virus moderates the relationship between authoritarianism and political attitudes toward the nation and out-groups. In line with the abovementioned interactionist perspectives, we argue that the perception of this existential threat will interact with authoritarianism, increasing its influence on in-group favoritism and out-group derogation (Feldman, 2003). What makes our study novel, however, is that this threat is not inherently derived from political or cultural contestation nor from the deliberate actions of a hostile out-group (Kossowska et al., 2011). Although important political actors, including those from the Trump

\footnotetext{
'The University of Sheffield, United Kingdom

${ }^{2}$ Royal Holloway, University of London, United Kingdom

${ }^{3}$ Research Department of Clinical, Educational and Health Psychology, University College London, United Kingdom

${ }^{4}$ Ulster University, United Kingdom

${ }^{5}$ Liverpool University, United Kingdom

${ }^{6}$ Maynooth University, Republic of Ireland

${ }^{7}$ Edinburgh Napier University, United Kingdom

${ }^{8}$ Trinity College Dublin, The University of Dublin, Republic of Ireland
}

Corresponding Author:

Todd K. Hartman, The University of Sheffield, 219 Portobello Street, Sheffield SI 4DP, United Kingdom.

Email: t.k.hartman@sheffield.ac.uk 
administration, have used political rhetoric to attach blame to other countries or immigrants (e.g., "Chinese virus" or "Wuhan virus"; Kuo, 2020; Nossem, 2020; Vazquez \& Klein, 2020; Zarhloule, 2020), COVID-19 poses an indiscriminate and inherently global existential threat with no delimited enemy. Using nationally representative survey data collected from two European countries during the initial phases of the COVID-19 global pandemic, we investigate the following research question: Does the existential threat from COVID-19 strengthen the relationship between authoritarianism and prejudicial political attitudes?

\section{Theory and Expectations}

According to Strong (1990, p. 249), large-scale epidemics of fatal diseases present serious obstacles to social order by producing "fear, panic, stigma, moralising and calls to action," effects that are most pronounced when a disease is "new, unexpected, or particularly devastating." J. Drury and Tekin Guven (2020), however, critique this "panic narrative," pointing out that collective behavior in emergencies is more complex than this perspective suggests (see also J. Drury et al., 2013; Ntontis et al., 2019). In particular, while they can instill suspicion of others and the fear that they might transmit the disease, leading to prejudicial attitudes and behaviors (Adida et al., 2020; Strong, 1990), pandemics can also inspire acts of unity, compassion, and solidarity (Aguirre et al., 2011; D. Drury et al., 2009; Ntontis \& Rocha, 2020; Solnit, 2009), especially when there is a sense of shared fate (J. Drury et al., 2019). Nevertheless, from the initial stages of the current COVID-19 pandemic, there have been reports of increased violence against people from Black and minority ethnic backgrounds, particularly targeted against people from Asian communities (Aratani, 2020; Campbell, 2020). In addition, far-right political groups have reportedly used the pandemic to promote anti-immigration and anti-Muslim attitudes (British Broadcasting Corporation, 2020; J. Wilson, 2020).

Early work on the COVID-19 pandemic also noted an increase in nationalistic rhetoric to promote both the acceptance of legitimate measures designed to prevent the spread of disease and authoritarian policies disguised as such (Nossem, 2020; Zarhloule, 2020). Other research has demonstrated that perceived existential threat from the COVID-19 pandemic increases prejudicial attitudes toward out-groups, such as the Chinese (Tabri et al., 2020). Scholars have also documented a positive relationship between certain types of COVID-19 media exposure and the expression of prejudice toward foreigners (Sorokowski et al., 2020). However, much of this early work has not examined the role of classic psychological predictors of prejudice toward out-groups, such as RWA or social dominance orientation (SDO), nor has it fully investigated the joint effect of predictors of prejudice and threat on prejudicial attitudes. More research on these predictors is warranted.

\section{RWA and SDO}

Classic work demonstrated the link between authoritarianism and ethnocentrism (Adorno et al., 2019), and more recent research has established both RWA and SDO, two individual-level right-wing dimensions, as robust, independent predictors of prejudice and intolerance (Altemeyer, 1981; Crawford \& Pilanski, 2014; Diaz-Veizades et al., 1995; Duckitt, 2001; Sibley et al., 2006; M. Wilson \& Sibley, 2013). In Duckitt's (2001, 2009) dual-process motivational model, both RWA and SDO are conceptualized as value-attitude-belief dimensions that interact with social environmental factors. Early social and environmental experiences favor or cause personality dispositions; in turn, these dispositions encourage different worldviews, which then interact to generate motivational goals, such as the motivational goal of threat control. Finally, value-attitude-belief dimensions, such as RWA or SDO, represent expressions of these motivational goals (Duckitt, 2001, 2009).

While the motivational goals behind these dimensions are chronically salient, external conditions can heighten their activation, and both RWA and SDO appear to be reactive to external circumstances (Duckitt, 2001, 2006, 2009; Duckitt et al., 2010; Duckitt \& Fisher, 2003; Duckitt \& Sibley, 2009, 2010; Feldman \& Stenner, 1997). However, RWA is in part an ideological response to fear, threat, and uncertainty, and only for RWA, not SDO, do attitudinal manifestations appear to be consistently responsive to threat (Lindén et al., 2018; Mirisola et al., 2014; Oyamot et al., 2006; Rickert, 1998; Sibley et al., 2006; Stenner, 2005). For example, RWA interacts with the perception of threat to both increase support for antidemocratic policies, such as increased governmental surveillance power, and to decrease support for human rights (Cohrs et al., 2007; Kossowska et al., 2011). Moreover, people high in RWA are motivated to support any measures they perceive to be protective of the in-group regardless of negative consequences, including the use of violence to address social problems (Fetchenhauer \& Bierhoff, 2004; Kossowska et al., 2011). The characteristics of prejudice associated with RWA also reflect its underlying cognitive and motivational schemas (Duckitt, 2001). Individuals high in RWA typically characterize out-groups as disorderly, immoral, deviant, and threatening to in-group safety; conversely, in-group members are normal, socially conforming, moral, and under threat from out-groups (Duckitt, 2001; Jackson \& Gaaertner, 2010; Shaffer \& Duckitt, 2013).

High levels of RWA and SDO are thus associated with less favorable attitudes toward migrant groups (Craig \& Richeson, 2014; Duckitt \& Sibley, 2010; Oyamot et al., 2006; Perry et al., 2015). Indeed, both RWA and SDO predict an increased willingness to engage in the active persecution of immigrants, though the situations that prime this response in people high in RWA and SDO are different: Those high in RWA are more willing to engage in the active persecution of immigrants who are unwilling to assimilate to the predominant culture, while those high in SDO are more likely to persecute immigrants who are willing to assimilate (Thomsen et al., 2008). Furthermore, 
Duckitt and Sibley (2010) found that RWA predicts opposition to immigration only when the immigrant group is perceived to be an economic or cultural threat, while SDO consistently predicts negative attitudes toward immigrants irrespective of perceived threat. Perry et al. (2015) also demonstrated that RWA can suppress the pro-social and pro-immigrant effect of other dimensions, including religiosity. Finally, higher levels of RWA also predict higher levels of nationalism, belief in the superiority of one's own nation, patriotism, and attachment to one's country and the values for which it stands (Osborne et al., 2017).

Despite this evidence, little is known about exactly how RWA and SDO might interact with the existential threat posed by a global outbreak of a lethal, contagious disease to affect wider expressions of authoritarian attitudes. There is, however, some instructive research in this area, though it does tend to be predicated upon different (and sometimes competing) psychological processes for RWA and SDO, which has implications for different causal models. For instance, Mirels and Dean (2006) found that those scoring higher in RWA overestimated the proportion of LGBTQ(IA + ) people living with HIV, while Collani et al. (2010) found that both RWA and SDO predicted prejudice toward people living with HIV or AIDS, effects which were partially mediated by (false) beliefs about the personal risk of infection. Likewise, upon investigating attitudes related to the Ebola epidemic in a German sample, Stürmer et al. (2017) reported that the relationship between RWA and support for quarantining African migrants and closing the border was mediated by normative threat. Meanwhile, however, Green et al. (2010) discovered that SDO mediated the relationships between germ aversion and support for assimilationist immigration criteria, health immigration criteria, and the desire to reduce the percentage of foreigners.

In short, we believe that there is scope to test classic theories of RWA and SDO during the current global pandemic, particularly with respect to the former's sensitivity to threat. We thus hypothesize that disease-related threat will moderate the relationship between RWA and ethnocentric attitudes: As levels of existential threat increase, so too should the association between RWA and ethnocentric attitudes (i.e., nationalism and anti-immigrant sentiment). In contrast, we do not expect disease-related threat to moderate the association between SDO and prejudicial attitudes.

\section{Data and Method}

We analyze national survey data collected from the United Kingdom (UK) and the Republic of Ireland (ROI) during the early phases of lockdown in both countries as part of the COVID-19 Psychological Research Consortium (C19PRC) Study. C19PRC is a longitudinal, multicountry study that aims to assess the psychological, social, economic, and political impact of the COVID-19 virus in the general population (McBride et al., 2020). The first waves of the study, C19PRC-UKW1 in the UK and C19PRC-ROIW1 in the ROI, involved the recruitment of large national samples of adults from the $\mathrm{UK}(N=2,025)$ and Ireland $(N=1,041)$ by the survey company Qualtrics. Data for the UK were collected between March 23 and 28, 2020, approximately 8 weeks after the first confirmed COVID-19 case there and during a time of rapidly increasing infections (strict lockdown measures were announced by the British prime minister on March 23, the same day our survey was fielded). Data for the Irish sample were collected between March 31 and April 5, 2020, approximately 4 weeks after the first confirmed case of COVID-19 in Ireland (and 2 days after the Irish taoiseach announced that people were not to leave their homes except for very limited purposes).

Research suggests that Qualtrics approximates probabilitybased samples reasonably well when quotas are used (e.g., demographic characteristics and responses to other sociopolitical questions; Zack et al., 2019). Thus, we employed stratified quota sampling methods to ensure that the data collected were representative in terms of age, sex, and household income in the UK and the same demographic indicators plus geographic region in Ireland. Subsequent checks confirmed sample representativeness in terms of the number of people in the household and other important sociodemographic characteristics (for details of recruitment, sampling, and the complete list of measures administered, see McBride et al., 2020). The full panel data set will be deposited to the UK Data Archive and Open Science Framework (OSF; https://osf.io/v2zur/) approximately 6 months after data collection for the project has been completed.

\section{Key Measures}

Nationalism. British/Irish nationalism was assessed by two items adapted from Davidov (2011): (1) "The world would be a better place if people from other countries were more like the British/Irish" and (2) "Generally speaking, Britain/Ireland is a better country than most other countries." Responses were measured on 5-point Likert-type scales ranging from 1 strongly disagree to 5 strongly agree. These items were combined into a single scale ranging from 0 to 1 (UK: $M=.55$, $S D=.24$, Cronbach's $\alpha=.80$; ROI: $M=.62, S D=.21$, Cronbach's $\alpha=.70$ ). The exact question wording for these and other psychological measures in this study, as well as descriptive statistics, are available in Tables A1 and A2 in the Supplemental Appendix, respectively.

Anti-immigrant sentiment. Three items from the British Social Attitudes Survey (2015) were used to assess respondents' attitudes toward migrants: (1) "Would you say it is generally bad or good for Britain's/Ireland's economy that migrants come to Britain/Ireland from other countries?" (using a 10-point scale ranging from 1 extremely bad to 10 extremely good; reverse coded and scaled from 0 to 1 to indicate anti-immigration attitudes; UK: $M=.41, S D=.26$; ROI: $M=.41, S D=.26$ ); (2) "Would you say that Britain's/Ireland's cultural life is generally undermined or enriched by migrants coming to live here from other countries?" (using a 10-point scale ranging from 1 undermined to 10 enriched; reverse coded and scaled from 0 to 1 ; UK: $M=.44, S D=.28$; ROI: $M=.41, S D=.27$ ); and 
Table I. Zero-Order Correlation Matrix Among Key Variables (UK Below Diagonal, Ireland Above Diagonal).

Republic of Ireland

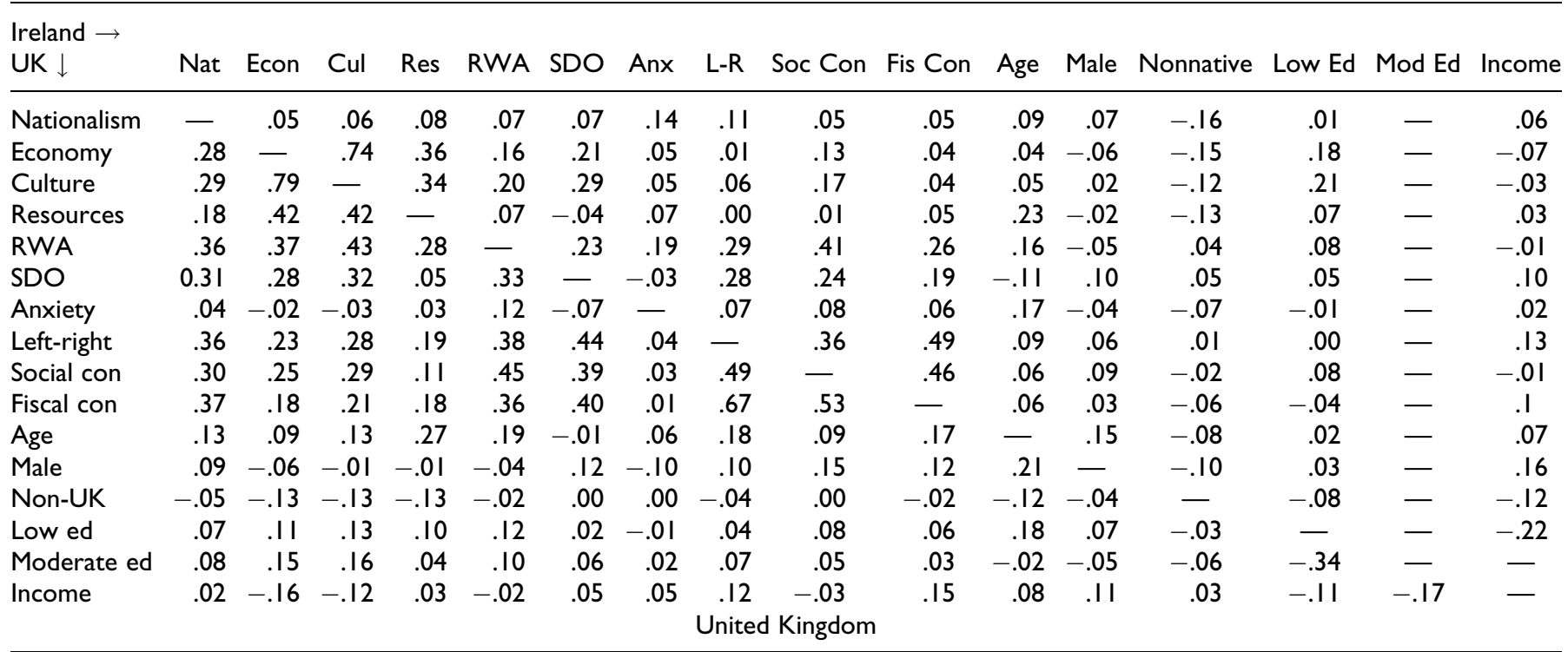

Note. Cell entries contain zero-order correlation coefficients (Pearson's $r$ ). Data from the United Kingdom $(N=2,025)$ presented below the diagonal; Republic of Ireland $(N=\mathrm{I}, 04 \mathrm{I})$ presented above the diagonal. UK = United Kingdom; RWA = right-wing authoritarianism; SDO = social dominance orientation.

(3) "Some migrants make use of Britain's/Ireland's schools, increasing the demand on them. However, many migrants also pay taxes that support schools and some also work in schools. Do you think that, on balance, migration to Britain/Ireland reduces or increases pressure on the schools across the whole of Britain/Ireland?" (using a 5-point scale ranging from 1 reduces pressure a lot to 5 increases pressure a lot; scaled to range from 0 to 1 ; UK: $M=.60, S D=.25$; ROI: $M=.59$, $S D=.25)$.

RWA. The six-item Very Short Authoritarianism Scale (Bizumic \& Duckitt, 2018) was used to assess respondents' levels of RWA. Items include "What our country needs most is discipline, with everyone following our leaders in unity"; "God's laws about abortion, pornography, and marriage must be strictly followed before it is too late"; and "Our society does NOT need tougher government and stricter laws" (reverse worded). Responses were collected on a 5-point Likert-type scale ranging from 1 strongly disagree to 5 strongly agree. Bizumic and Duckitt (2018) report satisfactory internal consistency and predictive validity; these six items were combined into a single scale ranging from 0 to 1 (UK: $M=.51$, $S D=.17$, Cronbach's $\alpha=.67$; ROI: $M=.52, S D=.17$, Cronbach's $\alpha=.58$ ).

SDO. Respondents' levels of social dominance were assessed using the 8-item $\mathrm{SDO}_{7}$ scale (Ho et al., 2015). Respondents were asked the extent to which they opposed/favored statements such as: "An ideal society requires some groups to be on top and others to be on the bottom"; "some groups of people are simply inferior to other groups"; and "we should do what we can to equalize conditions for different groups" (reverse scored). Responses ranged from 1 strongly oppose to 5 strongly favor on a 5-point Likert-type scale. Ho et al. (2015) report good criterion and construct validity; these eight items were combined into a single ranging from 0 to 1 (UK: $M=.36$, $S D=.18$, Cronbach's $\alpha=.84$; ROI: $M=.41, S D=.21$, Cronbach's $\alpha=$.79).

COVID-19 anxiety (proxy for existential threat). Respondents were asked "How anxious are you about the coronavirus COVID-19 pandemic?" and responded by positioning a slider anchored by 0 not at all anxious and 100 extremely anxious. This produced continuous scores ranging from 0 to 100 with higher scores reflecting higher levels of COVID-19-related anxiety; for ease of interpretation, we rescaled this item to range from 0 to 1 (UK: $M=.68, S D=.25$; ROI: $M=.72, S D=.24$ ). Importantly, this question was asked after we measured attitudes toward our key outcomes and psychological constructs to avoid inadvertently priming responses to RWA, SDO, nationalism, and anti-immigrant sentiment.

Political and ideological orientations. Three questions, adapted from the 2014 to 2023 British Election Study (2017), asked respondents how they would describe their (1) political orientation (on a 10-point scale ranging from 1 left wing to 10 right wing; rescaled to range from 0 to 1 ; $\mathrm{UK}: M=.48, S D=.21$; ROI: $M=.46, S D=.21$ ); (2) ideological orientation toward fiscal issues such as taxes and government spending (on a 10-point scale from 1 very liberal to 10 very conservative; rescaled to range from 0 to 1 ; $\mathrm{UK}: M=.49, S D=.22$; ROI: $M=.47, S D=.22$ ); and (3) ideological orientation toward 
Table 2. Regression Results from the United Kingdom.

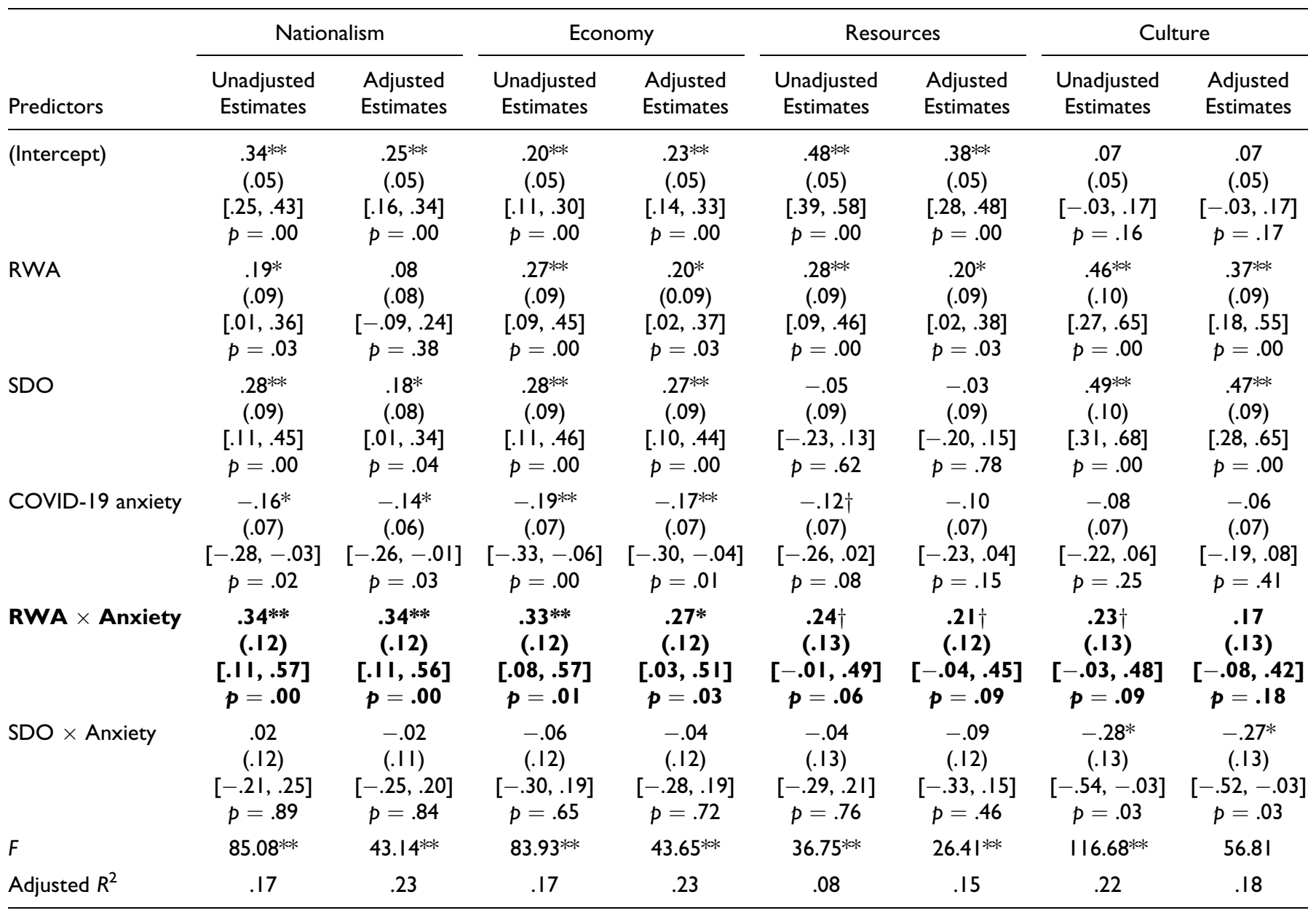

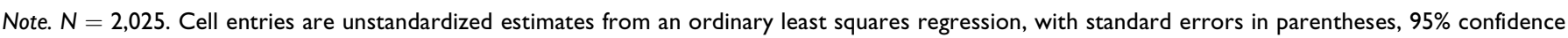

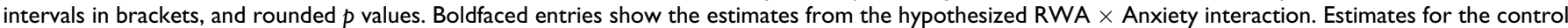

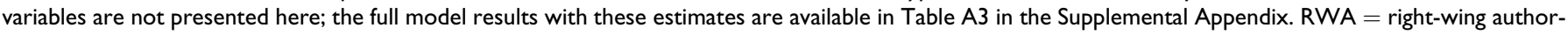
itarianism; SDO = social dominance orientation

$*_{p}<.05$. **p $<.01 . \dagger p<.10$.

social issues such as abortion and same-sex marriage (on a 10 -point scale from 1 very liberal to 10 very conservative; rescaled to range from 0 to 1 ; $\mathrm{UK}: M=.36, S D=.27$; ROI: $M=.35, S D=.31)$.

Sociodemographic control variables. Participants self-reported their age (in years; rescaled from 0 to 1 for interpretability; $\mathrm{UK}: M=.42 ; S D=.24$; ROI: $M=.39, S D=.23$ ); gender (dummy coded with females plus six respondents with nontraditional gender identities in the UK and three in Ireland serving as the reference category; UK: $M=.48, S D=.50$; ROI: $M=.48, S D=.50$ ); educational attainment (dummy coded with those having earned a bachelor's degree or higher as the reference category; in the UK, low education indicates those who have no formal qualifications or only technical qualifications, $M=.13, S D=.34$, while moderate education refers to those with General Certificates of Secondary Education (GCSEs), A levels, or diplomas, $M=.43, S D=.49$; in Ireland, low education identifies anyone who below a postsecondary qualification, $M=.30, S D=.46$ ); gross household income in 2019 (UK: five income bands rescaled from 0 to $1 ; M=$ $.50, S D=.36$; ROI: 10 income bands rescaled from 0 to 1 ; $M=.25, S D=.24)$; and whether they were born outside of the country (dummy coded with those born in the UK/Ireland as the reference category; UK: $M=0.09, S D=.29$; ROI: $M=$ $.29, S D=.46)$.

The zero-order correlations for all measures are presented in Table 1.

\section{Results}

To test whether existential threat moderates the association between authoritarianism and political attitudes, we regressed nationalism and the three anti-immigrant sentiment outcomes on RWA, COVID-19 anxiety, and their interaction (product term), as well as SDO (and its interaction with COVID-19 anxiety) and other sociodemographic control variables. The condensed results of these regressions are presented in Table 2 
Table 3. Regression Results From the Republic of Ireland.

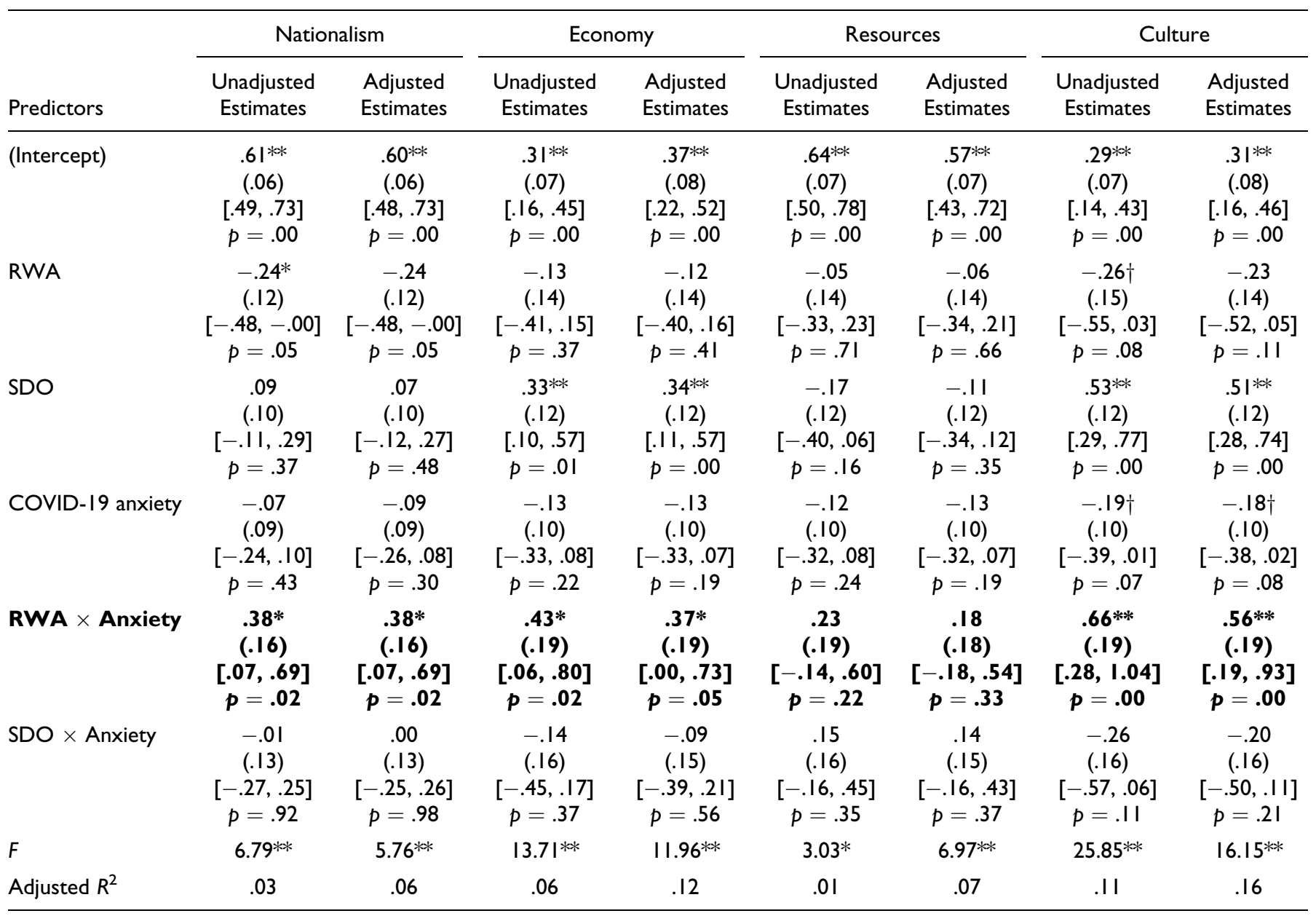

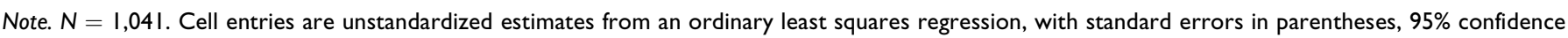

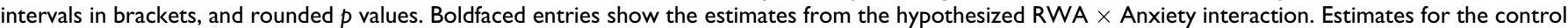

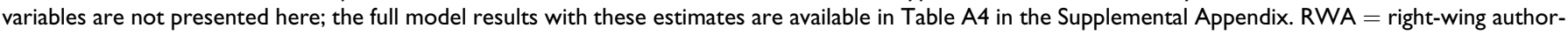
itarianism; SDO = social dominance orientation.

$*_{p}<.05$. **p $<.01 . \dagger p<.10$.

for the UK and Table 3 for the Irish data (the full model results are available in Tables A3 and A4 in the Supplemental Appendix). Ordinary least squares regression was used to estimate all models because of the pseudo-continuous nature of the outcomes and for ease of interpretation; however, the results do not differ substantially if we estimate models with ordinal outcomes using ordered logistic regression. The $R$ code and output used for all data manipulation and analyses are available on the OSF website (https://osf.io/w5ktb/).

To begin, the RWA $\times$ COVID-19 Anxiety interaction is in the hypothesized direction (positively signed) in all of the regression models that we conducted using data from two different countries. In other words, the estimated effect of RWA increases in conjunction with perceived anxiety about the threat posed by COVID-19, and the size of these estimates is relatively large compared to other predictors in the models using the same 0 to 1 scale (see Table A3 for the full set of estimates). In the UK data (Table 2), the estimates for the unadjusted (without demographic and political covariates) interaction between RWA and anxiety are statistically significant at the .05 level for two of the four outcomes: COVID-19 anxiety moderates the effect of RWA on nationalism $(b=.34$, standard error $[S E]=.12, p=.00$; two-tailed) and anti-immigrant sentiment related to the economy ( $b=.33, S E=.12, p=.01$; two-tailed). The interaction is significant at the .10 level for the outcomes related to the notion that immigrants place pressure on resources $(b=.24, S E=.13, p=.06)$ and harm culture $(b=.23, S E=.13$, $p=.09$; two-tailed). Importantly, these interaction effects are very similar even after introducing a range of sociodemographic and political covariates (i.e., the "adjusted" estimates).

In the Irish data (Table 3), the estimates for the unadjusted interaction between RWA and anxiety are statistically significant at the .05 level for three of the four outcomes: COVID-19 anxiety moderates the effect of RWA on nationalism $(b=.38$, $S E=.16, p=.02$; two-tailed), immigrants hurt the economy ( $b=.43, S E=.19, p=.02$; two-tailed), and immigrants harm culture ( $b=.66, S E=.19, p=.00$; two-tailed). The interaction is not statistically significant for the outcome related to 


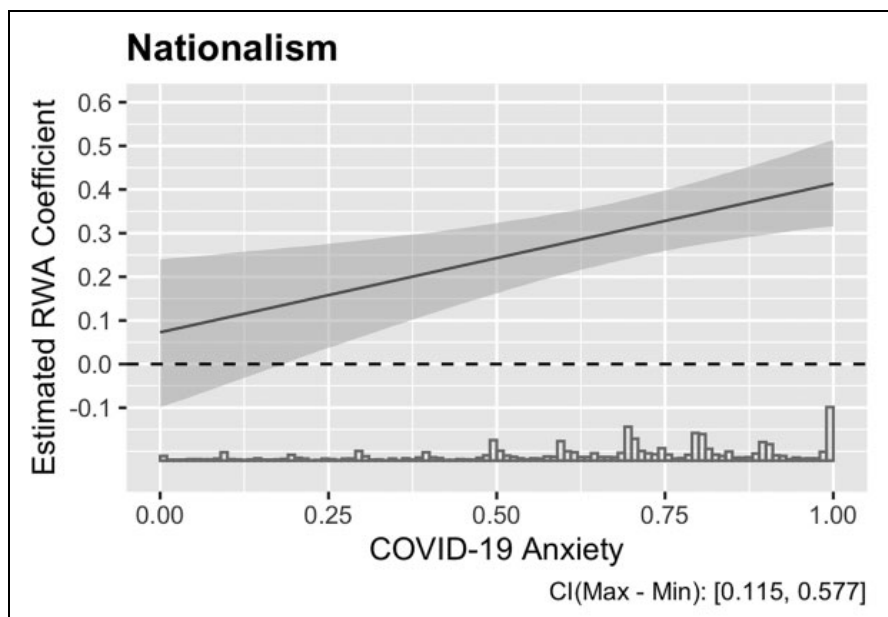

Resources

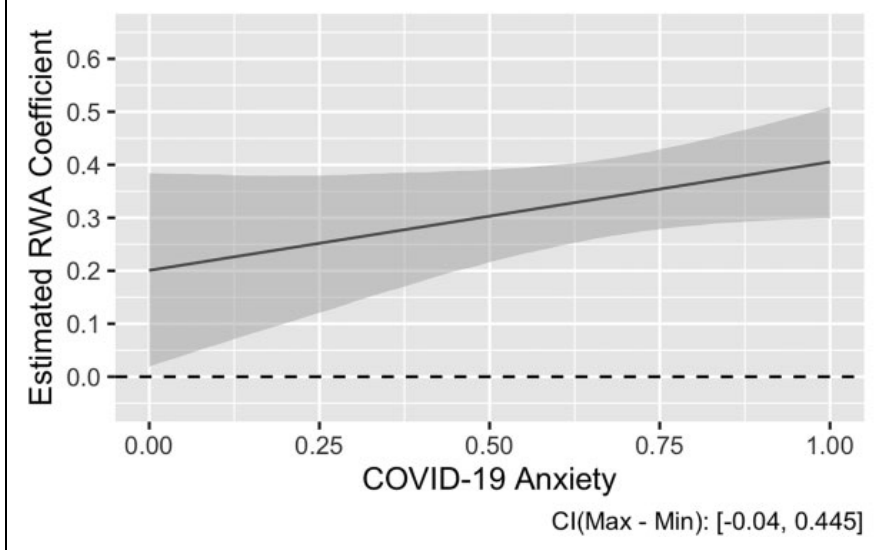

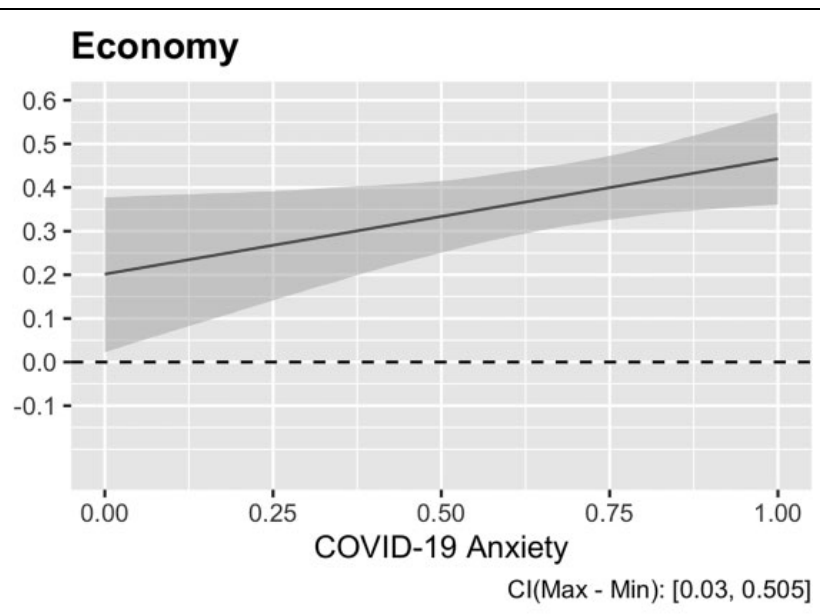

\section{Culture}

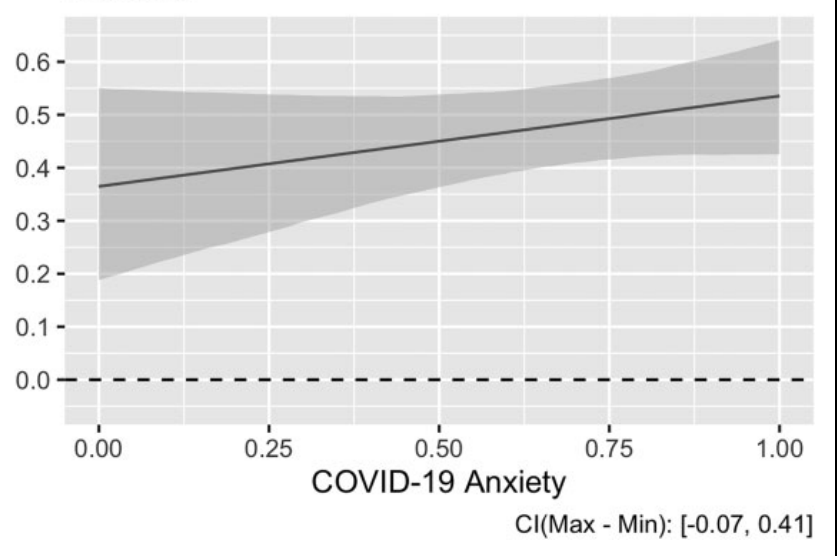

Figure I. Conditional effect of right-wing authoritarianism (RWA) on nationalism and anti-immigrant sentiment at different levels of COVID-I9 anxiety in the United Kingdom. Note: Each plot shows the estimated conditional effect of RWA on the outcome listed in bold at different levels of disease-related anxiety based on the adjusted estimates (i.e., full model with covariates) from Table 2 using the "interplot" package in $R$. The distribution of the moderator (COVID-19 anxiety) is displayed above the $x$-axis in the upper left panel; $95 \%$ confidence intervals are shaded in gray. The caption in the bottom right corner of each plot contains the confidence intervals of the difference between the conditioned effects of anxiety at the minimum and maximum values authoritarianism. The plots suggest that the estimated effect of RWA increases as levels of anxiety rise.

resources $(b=.23, S E=.19, p=.22)$. Once again, these interaction effects are largely unchanged in terms of their estimated effect and statistical significance even after introducing a range of sociodemographic and political covariates. ${ }^{1}$ In sum, we take the results from the UK and Ireland as strong evidence supporting our expectation regarding the interaction between RWA and COVID-19 threat.

In contrast, the SDO $\times$ COVID-19 Anxiety interaction is in the wrong direction in three of the four unadjusted models in both the UK (Table 2) and Ireland (Table 3); the results do not change when covariates are included in the models. Moreover, the SDO $\times$ Anxiety interaction is only statistically significant for the outcome related to culture in the Irish $(b=-.28$, $S E=.13, p=.03$; two-tailed), but again, this effect is in the wrong direction implying that as threat increases, the coefficient for SDO decreases. None of the SDO $\times$ Anxiety interactions are statistically significant in the UK data. These results suggest that disease-related threat does not moderate the effect of SDO and political attitudes.

It is also worth noting that in the UK data, right-wing political views and conservative ideological orientations are generally associated with increased levels of nationalism and anti-immigrant sentiment (though fiscal conservatives appear less likely to report that immigrants harm culture, social conservatives are less likely to report that immigrants pressure resources), as are those at lower levels of educational attainment. There is a small gender effect across all models suggesting that men are slightly more nationalistic but less likely to hold anti-immigrant views - again, these estimates are relatively small compared to other covariates. Older individuals appear more likely to associate immigrants with placing additional pressure on material resources and being bad for the cultural life of Britain, while those with higher incomes are less likely to state that immigrants are bad for Britain's economy. Finally, 


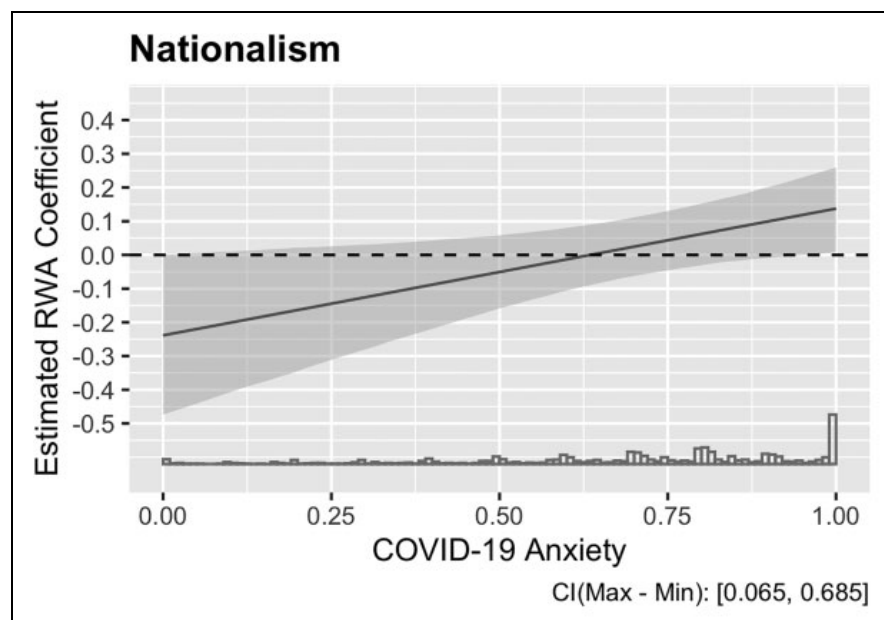

Resources

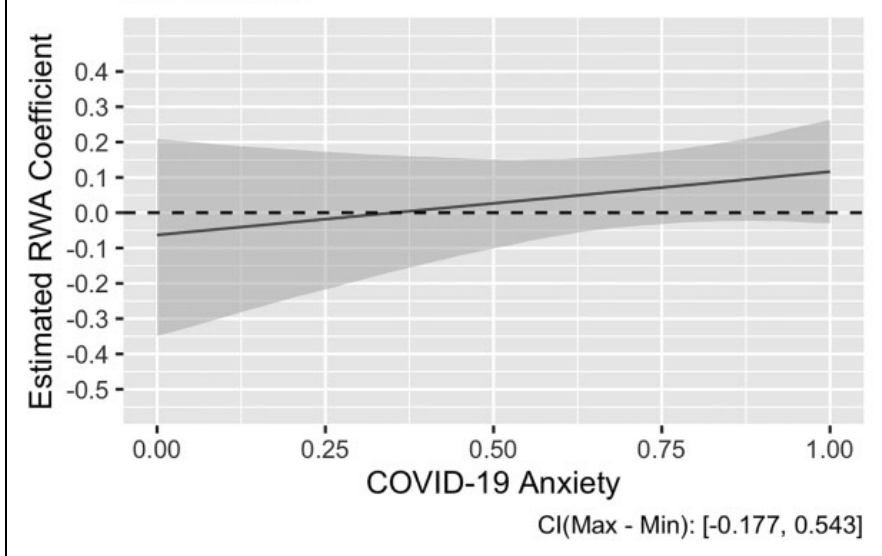

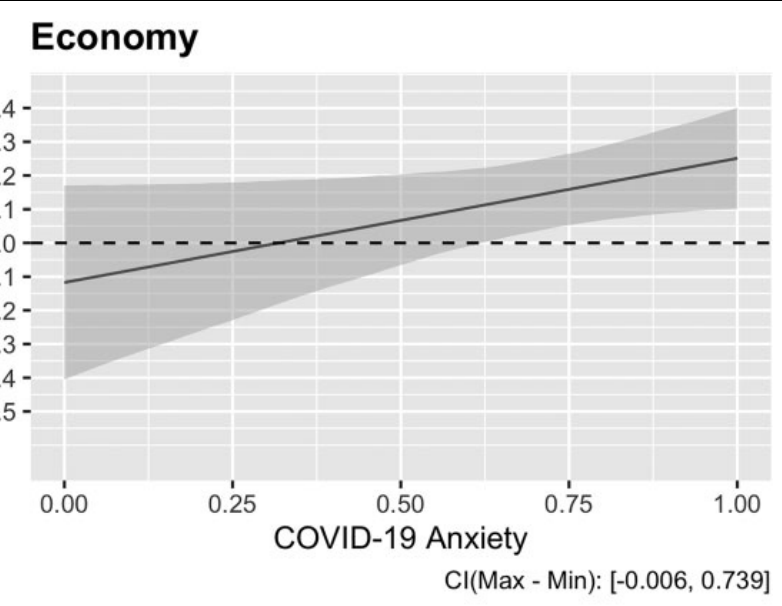

\section{Culture}

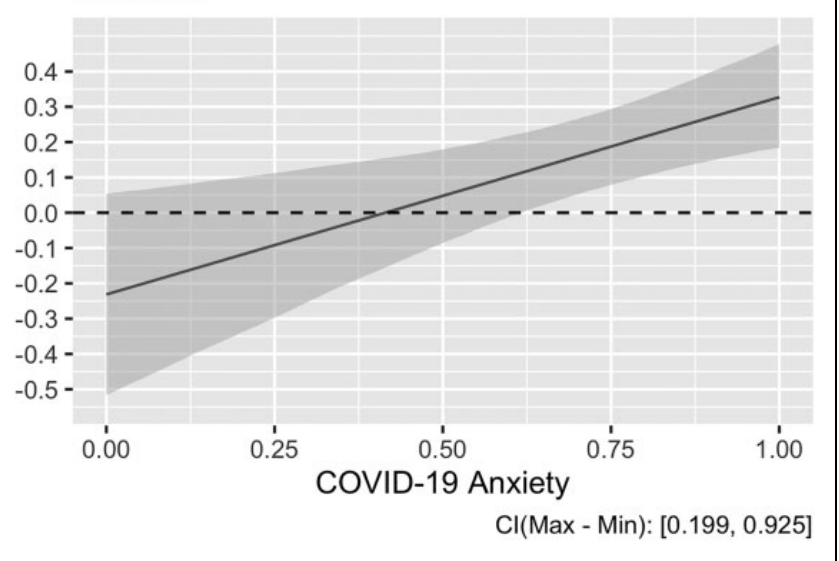

Figure 2. Conditional effect of right-wing authoritarianism (RWA) on nationalism and anti-immigrant sentiment at different levels of COVID-I9 anxiety in the Republic of Ireland. Note: Each plot shows the estimated conditional effect of RWA on the outcome listed in bold at different levels of anxiety based on the adjusted estimates (i.e., full model with covariates) from Table 3 using the "interplot" package in $R$. The distribution of the moderator (COVID- 19 anxiety) is displayed above the $x$-axis in the upper left panel; $95 \%$ confidence intervals are shaded in gray. The caption in the bottom right corner of each plot contains the confidence intervals of the difference between the conditioned effects of anxiety at the minimum and maximum values authoritarianism. The plots suggest that the estimated effect of RWA increases as levels of anxiety rise.

those born outside the UK are perhaps unsurprisingly less likely to hold anti-immigrant attitudes.

Examining the sociopolitical covariates from the Irish data (Table 3), we see that the statistically significant predictors are necessarily political or ideological orientations. Instead, low educational attainment is consistently associated with negative attitudes toward immigrants. As we saw with the UK data, respondents who were foreign-born were more likely to hold ethnocentric views.

To investigate the dynamics of the RWA $\times$ COVID-19 Anxiety interactions in more detail, we plotted the changes in the conditional coefficient of authoritarianism as a function of COVID-19 anxiety in Figure 1 for the UK and Figure 2 for Ireland using the "interplot" package in $R$ (predicted values for each outcome are presented in Figure A1 in the Supplemental Appendix). Scholars recommend that conditional effects are calculated from the marginal effect at every observed value of the moderator; in this case, COVID-19 anxiety, to properly interpret interactions (e.g., see Berry et al., 2012; Brambor et al., 2006). The plots clearly demonstrate that the RWA $\times$ COVID-19 interaction is both statistically and substantively interesting: The effect of RWA on nationalism and anti-immigrant sentiment increases substantially in conjunction with heightened perceptions of existential threat from the COVID-19 pandemic in both countries. Comparing the figures from both countries, we see that the coefficient for RWA is statistically significant throughout the entire range of values of COVID-19 anxiety moderator in the UK. However, in Ireland, the estimate for RWA only reaches statistical significance at relatively high levels of disease-related threat (i.e., the upper quartile of the anxiety distribution).

\section{Discussion}

Our study contributes to the literature on RWA and SDO by demonstrating that existential disease-related threats appear to moderate authoritarian predispositions, thus influencing their expression on ethnocentric political attitudes. Using data 
from two large, nationally representative samples of adults in the UK and ROI collected during the initial phases of strict lockdown measures in those countries, we find that while authoritarianism is associated with a nonzero effect on nationalism and anti-immigrant sentiment at low levels of anxiety (and in fact, negative association in Ireland), the overall impact of RWA is rather small. Only when perceived threat - operationalized here as a measure of anxiety about the COVID-19 pandemic - is high does RWA exert a substantial effect on those nationalism and anti-immigration attitudes. This is interesting because most extant literature examines how threats from specific out-groups activate authoritarian predispositions and generate backlashes against those same out-groups. Here, the threat does not arise from an inherently threatening out-group but a virus; yet authoritarians still respond by becoming more nationalistic and more anti-immigrant.

There are, of course, some limitations of our study that merit discussion. First, the cross-sectional nature of our data means that it is impossible to disentangle the causal relationships among RWA, threat, nationalism, and anti-immigrant sentiment. For instance, when COVID-19 anxiety is regressed on RWA, SDO, and the other sociodemographic control variables used in our prior analyses, we find that RWA is a statistically significant and positively signed predictor of perceived anxiety in both the $\mathrm{UK}(b=.19, S E=.04, p=.00)$ and Irish $(b=.24, S E=.05$, $p=.00$ ) samples, as is age and income (UK only). Interestingly, SDO is negatively associated with COVID-19 anxiety (UK: $b=-.17, S E=.04, p=.00$; ROI: $b=-.06, S E=.04$, $p=.10$ ), along with being male and non-native-born (ROI only). Thus, the relationships we have modeled are likely more nuanced than the cross-sectional data can handle. Second, while our sample is large and nationally representative, it is not a probability-based sample, which means that there may be individuals with differential probabilities of selection into the study with unknown (and unknowable) effects on our key measures. Third, we used a single proxy of anxiety related to the COVID-19 pandemic as a measure of existential threat; in hindsight, it would have been better to have multiple, direct measures of our threat moderator, given its hypothesized role in moderating RWA. Finally, we only assessed attitudes toward nationalism and immigration, but one could imagine a number of other interesting outcomes that may be predicted by the intersection of existential threat and authoritarianism.

Future research should build upon our work by investigating the nature and consequences of existential threat on RWA and SDO, as well as its interactive effect on political attitudes and behavior toward in- and out-groups. One way to gain traction on this problem would be to design longitudinal studies to examine how threats at one time period affect subsequent political attitudes. It would be particularly interesting to know whether our findings are unique to the UK and Ireland or whether they would replicate in other non-Western societies (we suspect that they would but acknowledge it is an empirical question).

Ultimately, we believe that our findings are important because they portend the likely consequences of public opinion in countries across the world. That is, grave threats to humanity from the
COVID-19 pandemic appear to activate authoritarians in society, which in turn shifts opinion toward nationalistic and anti-immigrant sentiments. One can only imagine how this might affect governance in democracies in Europe, North America, and elsewhere in the world as the global pandemic continues.

\section{Declaration of Conflicting Interests}

The author(s) declared no potential conflicts of interest with respect to the research, authorship, and/or publication of this article.

\section{Funding}

The initial stages of this project were supported by start-up funds from the University of Sheffield (Department of Psychology, the Sheffield Methods Institute, and the Higher Education Innovation Fund via an Impact Acceleration grant administered by the university) and by the Faculty of Life and Health Sciences at Ulster University. The research was subsequently supported by the ESRC (grant ref. ES/V004379/1): 'A longitudinal mixed-methods population study of the UK during the COVID-19 pandemic: Psychological and social adjustment to a global threat'. TKH, JGM, LL, LM, OM, JM, MS, KB, and RPB received financial support from this grant for the submitted work.

\section{ORCID iD}

Todd K. Hartman (D) https://orcid.org/0000-0001-9136-2784

\section{Supplemental Material}

The supplemental material is available in the online version of the article.

\section{Note}

1. We also calculated adjusted $p$ values for the false discovery ratethat is, the expected proportion of false discoveries among the rejected hypotheses - using a Benjamini and Hochberg (1995) method from the "multcomp" (version: 1.14-14) package in $R$. Overall, the RWA $\times$ Anxiety interaction was statistically significant at the $p<.05$ level (two-tailed) in three of eight models from the United Kingdom and Ireland and at the $p<.10$ in five of eight cases. These results are available in Table A5 in the Supplemental Appendix.

\section{References}

Adorno, T., Frenkel-Brenswik, E., Levinson, D. J., \& Sanford, R. N. (2019). The Authoritarian Personality. Verso Books.

Adida, C., Dionne, K., \& Platas, M. (2020). Ebola, elections, and immigration: How politicizing an epidemic can shape public attitudes. Politics, Groups, and Identities, 8(3), 488-514.

Aguirre, B. E., Torres, M. R., Gill, K. B., \& Hotchkiss, H. L. (2011). Normative collective behaviour in the station building fire. Social Science Quarterly, 92, 100-118. https://doi.org/10.1111/j.15406237.2011.00759.x

Altemeyer, B. (1981). Right-wing authoritarianism. University of Manitoba Press.

Aratani, L. (2020). 'Coughing while Asian': Living in fear as racism feeds off coronavirus panic. The Guardian. https://www.theguar dian.com/world/2020/mar/24/coronavirus-us-asian-americansracism 
Benjamini, Y., \& Hochberg, Y. (1995). Controlling the false discovery rate: A practical and powerful approach to multiple testing. Journal of the Royal Statistical Society: Series B, 57, 289-300.

Berry, W. D., Golder, M., \& Milton, D. (2012). Improving tests of theories positing interaction. The Journal of Politics, 74(3), 653-671.

Bizumic, B., \& Duckitt, J. (2018). Investigating right wing authoritarianism with a very short authoritarianism scale. Journal of Social and Political Psychology, 6(1), 129-150.

Brambor, T., Clark, W. T., \& Golder, M. (2006). Understanding interaction models: Improving empirical analyses. Political Analysis, 14(1), 63-82.

British Broadcasting Corporation. (2020). Coronavirus: Arrests over 'disgusting' racist Covid-19 stickers. https://www.bbc.co.uk/ news/uk-england-south-yorkshire-52314222

British Election Study. (2017). British election study 2017 face-toface survey v1.0: Release note. https://www.britishelectionstudy. com/wp-content/uploads/2019/01/BES-2017-F2F-codebook.pdf

British Social Attitudes Survey. (2015). Questionnaire. http://doc. ukdataservice.ac.uk/doc/8116/mrdoc/pdf/8116_bsa2015_documen tation.pdf

Campbell, L. (2020). Chinese in UK report 'shocking' levels of racism after coronavirus outbreak. The Guardian. https://www.theguar dian.com/uk-news/2020/feb/09/chinese-in-uk-report-shocking-lev els-of-racism-after-coronavirus-outbreak

Cohrs, J. C., Kielmann, S., Maes, J., \& Moschner, B. (2005). Effects of right-wing authoritarianism and threat from terrorism on restriction of civil liberties. Analyses of Social Issues and Public Policy, 5(1), 263-276.

Cohrs, J. C., Maes, J., Moschner, B., \& Kielmann, S. (2007). Determinants of human rights attitudes and behaviour: A comparison and integration of psychological perspectives. Political Psychology, 28(4), 441-469.

Collani, G., Grumm, M., \& Streicher, K. (2010). An investigation of the determinants of stigmatization and prejudice toward people living with HIV/AIDS. Journal of Applied Social Psychology, 40(7), 1747-1766.

Craig, M., \& Richeson, J. (2014). Not in my backyard! Authoritarianism, social dominance orientation, and support for strict immigration policies at home and abroad. Political Psychology, 35(3), 417-429.

Crawford, J., \& Pilanski, J. (2014). The differential effects of right-wing authoritarianism and social dominance orientation on political intolerance. Political Psychology, 35(4), 557-576.

Davidov, E. (2011). Nationalism and constructive patriotism: A longitudinal test of comparability in 22 countries with the ISSP. International Journal of Public Opinion Research, 23(1), 88-103.

Diaz-Veizades, J., Widaman, K., Little, T., \& Gibbs, K. (1995). The measurement and structure of human rights attitudes. The Journal of Social Psychology, 135(3), 313-328.

Drury, D., Cocking, C., \& Reicher, S. (2009). Everyone for themselves? A comparative study of crowd solidarity among emergency survivors. British Journal of Social Psychology, 48, 487-506.

Drury, J., Carter, H., Cocking, C., Ntontis, E., Tekin Guven, S., \& Amlôt, R. (2019). Facilitating collective psychosocial resilience in the public in emergencies: Twelve recommendations based on the social identity approach. Frontiers in Public Health, 7(141), 1-21.
Drury, J., Novelli, D., \& Stott, C. (2013). Representing crowd behaviour in emergency planning guidance: 'Mass panic' or collective resilience? Resilience, 1(1), 18-37. https://doi.org/10.1080/21693 293.2013.765740

Drury, J., \& Tekin Guven, S. (2020). Emergencies and disasters. In J. Jetten, S. D. Reicher, S. A. Haslam, \& T. Cruwys (Eds.), Together apart: The psychology of COVID-19 (pp. 80-83). Sage.

Duckitt, J. (2001). A dual-process cognitive-motivational theory of ideology and prejudice. Advances in Experimental Social Psychology, 33, 41-133.

Duckitt, J. (2006). Differential effects of right-wing authoritarianism and social dominance orientation on outgroup attitudes and their mediation by threat from and competitiveness to outgroups. Personality and Social Psychology Bulletin, 32(5), 684-696.

Duckitt, J. (2009). Authoritarianism and dogmatism. In M. Leary \& R. Hoyle (Eds.), Handbook of individual differences in social behaviour (pp. 289-317). Guildford Press.

Duckitt, J., Bizumic, B., Krauss, S., \& Heled, E. (2010). A tripartite approach to right-wing authoritarianism: The authoritarianconservatism-traditionalism model. Political Psychology, 31(5), 685-715.

Duckitt, J., \& Fisher, K. (2003). The impact of social threat on worldview and ideological attitudes. Political Psychology, 24(1), 199-222.

Duckitt, J., \& Sibley, C. (2009). A dual-process motivational model of ideology, politics, and prejudice. Psychological Inquiry, 20(2-3), 98-109.

Duckitt, J., \& Sibley, C. (2010). Right-wing authoritarianism and social dominance orientation differentially moderate intergroup effects on prejudice. European Journal of Personality, 24(7), 583-601.

Feldman, S. (2003). Enforcing social conformity: A theory of authoritarianism. Political Psychology, 24(1), 41-74.

Feldman, S., \& Stenner, K. (1997). Perceived threat and authoritarianism. Political Psychology, 18(4), 741-770.

Fetchenhauer, D., \& Bierhoff, H. (2004). Attitudes toward a military enforcement of human rights. Social Justice Research, 17(1), 75-92.

Green, E., Krings, F., Staerklé, C., Bangerter, A., Clémence, A., Wagner-Egger, P., \& Bornand, T. (2010). Keeping the vermin out: Perceived disease threat and ideological orientations as predictors of exclusionary immigration attitudes. Journal of Community \& Applied Social Psychology, 20, 299-316.

Hetherington, M. J., \& Suhay, E. (2011). Authoritarianism, threat, and Americans' support for the war on terror. American Journal of Political Science, 55(3), 546-560.

Ho, A. K., Sidanius, J., Kteily, N., Sheehy-Skeffington, J., Pratto, F., Henkel, K. E., Foels, R., \& Stewart, A. L. (2015). The nature of social dominance orientation: Theorizing and measuring preferences for intergroup inequality using the new $\mathrm{SDO}_{7}$ scale. Journal of Personality and Social Psychology, 109(6), 1003-1028.

Jackson, L., \& Gaaertner, L. (2010). Mechanisms of moral disengagement and their differential use by right-wing authoritarianism and social dominance orientation in support of war. Aggressive Behaviour, 36, 238-250.

Kossowska, M., Trejtowicz, M., Lemus, S., Bukowski, M., Van Hiel, A., \& Goodwin, R. (2011). Relationships between right-wing 
authoritarianism, terrorism threat, and attitudes towards restrictions of civil rights. British Journal of Psychology, 102, 245-259.

Kuo, L. (2020). Trump sparks anger by calling coronavirus the 'Chinese virus.' The Guardian. https:/www.theguardian.com/ world/2020/mar/17/trump-calls-covid-19-the-chinese-virus-asrift-with-coronavirus-beijing-escalates

Lavine, H., Lodge, M., \& Freitas, K. (2005). Threat, authoritarianism, and selective exposure to information. Political Psychology, 26(2), 219-244.

Lavine, H., Lodge, M., Polichak, J., \& Taber, C. (2002). Explicating the black box through experimentation: Studies of authoritarianism and threat. Political Analysis, 10(4), 343-361.

Lindén, M., Björklind, F., \& Bäckström, M. (2018). How a terror attack affects right-wing authoritarianism, social dominance orientation, and their relationship to torture attitudes. Scandinavian Journal of Psychology, 59, 547-552.

McBride, O., Murphy, J., Shevlin, M., Gibson-Miller, J., Hartman, T. K., Hyland, P., Levita, L., Mason, L., Martinez, A. P., McKay, R., Stocks, T. V., Bennett, K. M., Vallières, F., Karatzias, T., Valiente, C., Vazquez, C., \& Bentall, R. P. (2020). Monitoring the psychological impact of the COVID-19 pandemic in the general population: An overview of the context, design and conduct of the COVID-19 psychological research consortium (C19PRC) Study. International Journal of Methods in Psychiatric Research, e1861.

Merolla, J. L., \& Zechmeister, E. J. (2009). Democracy at risk: How terrorist threats affect the public. University of Chicago Press.

Mirels, H., \& Dean, J. (2006). Right-wing authoritarianism, attitude salience, and beliefs about matters of fact. Political Psychology, 27(6), 839-866.

Mirisola, A., Roccato, M., Russo, S., Spagna, G., \& Vieno, A. (2014). Societal threat to safety, compensatory control, and right-wing authoritarianism. Political Psychology, 35(6), 295-812.

Nossem, E. (2020). The pandemic of nationalism and the nationalism of pandemics (UniGR Centre for Border Studies Working Paper Vol. 8). https://ubt.opus.hbz-nrw.de/frontdoor/index/index/ docId/1405

Ntontis, E., Drury, J., Amlôt, R., Rubin, J. G., \& Williams, R. (2019). Community resilience and flooding in UK guidance: A review of concepts, definitions, and their implications. Journal of Contingencies and Crisis Management, 27, 2-13. https://doi.org/10.1111/ 1468-5973.12223

Ntontis, E., \& Rocha, C. (2020). Solidarity. In J. Jetten, S. D. Reicher, S. A. Haslam, \& T. Cruwys (Eds.), Together apart: The psychology of COVID-19 (pp. 84-87). Sage.

Osborne, D., Milojev, P., \& Sibley, C. (2017). Authoritarianism and national identity: Examining the longitudinal effects of SDO and RWA on nationalism and patriotism. Personality and Social Psychology Bulletin, 43(8), 1086-1099.

Oyamot, C., Borgida, E., \& Fisher, E. (2006). Can values moderate the attitudes of right-wing authoritarians? Personality and Social Psychology Bulletin, 32(4), 486-500.

Perry, R., Paradies, Y., \& Pedersen, A. (2015). Religious ambivalence: Suppression of pro-social attitudes toward asylum seekers by rightwing authoritarianism. The International Journal for the Psychology of Religion, 25(3), 230-246.
Rickert, E. J. (1998). Authoritarianism and economic threat: Implications for political behavior. Political Psychology, 19(4), 707-720.

Roccato, M., \& Russo, S. (2017). Right-wing authoritarianism, societal threat to safety, and psychological distress. European Journal of Social Psychology, 47(5), 600-610.

Roccato, M., Vieno, A., \& Russo, S. (2014). The country's crime rate moderates the relation between authoritarian predispositions and the manifestations of authoritarianism: A multilevel, multinational study. European Journal of Personality, 28(1), 14-24.

Sales, S. M. (1972). Economic threat as a determinant of conversion rates to authoritarian and nonauthoritarian churches. Journal of Personality and Social Psychology, 23, 420-428.

Shaffer, B., \& Duckitt, J. (2013). The dimensional structure of people's fears, threats, and concerns and their relationship with right-wing authoritarianism and social dominance orientation. International Journal of Psychology, 48(1), 6-17.

Sibley, C., Robertson, A., \& Wilson, M. (2006). Social dominance orientation and right-wing authoritarianism. Political Psychology, 27(5), 755-768.

Solnit, R. A. (2009). Paradise built in hell: The extraordinary communities that arise in disaster. Viking.

Sorokowski, P., Groyecka, A., Kowal, M., Sorokowska, A., Bialek, M., Lebuda, I., Zdybek, P., \& Karwowski, M. (2020). Information about pandemic increases negative attitudes toward foreign groups: A case of COVID-19 outbreak. https://psyarxiv.com/j23vt/

Stenner, K. (2005). The authoritarian dynamic. Cambridge University Press.

Strong, P. (1990). Epidemic psychology: A model. Sociology of Health and Illness, 12(3), 249-259.

Stürmer, S., Rohmann, A., Mazziotta, A., Siem, B., \& Barbarino, M. (2017). Fear of infection or justification of social exclusion? The symbolic exploitation of the Ebola epidemic. Political Psychology, 38(5), 499-513.

Tabri, N., Hollingshead, S. J., \& Wohl, M. J. A. (2020). Framing COVID-19 as an existential threat predicts anxious arousal and prejudice towards Chinese people. https://psyarxiv.com/mpbtr/

Thomsen, L., Green, E., \& Sidanius, J. (2008). We will hunt them down: How social dominance orientation and right-wing authoritarianism fuel ethnic persecution of immigrants in fundamentally different ways. Journal of Experimental Social Psychology, 44, 1455-1464.

Vazquez, M., \& Klein, B. (2020). Trump again defends use of the term 'China virus.' CNN. https:/edition.cnn.com/2020/03/17/politics/ trump-china-coronavirus/index.html

Wilson, J. (2020). Disinformation and blame: How America's far right is capitalizing on coronavirus. The Guardian. https://www.theguar dian.com/world/2020/mar/19/america-far-right-coronavirus-out break-trump-alex-jones

Wilson, M., \& Sibley, C. (2013). Social dominance orientation and right-wing authoritarianism: Additive and interactive effects on political conservatism. Political Psychology, 34(2), 277-284.

Zack, E. S., Kennedy, J., \& Long, J. S. (2019). Can nonprobability samples be used for social science research? A cautionary tale. Survey Research Methods, 15(2), 215-227.

Zarhloule, Y. (2020). Framing nationalism in times of a pandemic: The case of morocco [Special issue]. POMEPS Studies, 39, The COVID-19 Pandemic in the Middle East and North Africa, 55-56. 


\section{Author Biographies}

Todd K. Hartman is Senior Lecturer in Quantitative Social Science at the University of Sheffield. His research explores the psychological underpinnings of public opinion and political behaviour.

Thomas V.A. Stocks is a researcher affiliated with the University of Sheffield. He investigates how authoritarianism and other psychological constructs affect political attitudes.

Ryan McKay is Professor of Psychology at Royal Holloway University. His research aims to uncover the psychological, social, and evolutionary causes and consequences of biases in belief systems.

Jilly Gibson-Miller is Lecturer in Psychology at the University of Sheffield. She is a HCPC-Registered Health Psychologist and BACP-registered Psychotherapist with research interests in behaviour change, self-regulation, and public health.

Liat Levita is Senior Lecturer in Psychology at the University of Sheffield. Her research explores the neurobiological mechanisms underlying processes of cognition and emotion throughout development.

Anton P. Martinez is a doctoral student at the University of Sheffield. $\mathrm{He}$ is researching the role of explicit and implicit psychological processes in clinical and subclinical paranoia.

Liam Mason is Lecturer in Clinical Psychology at University College London. His work focuses on understanding the mechanisms of mood and decision-making, especially with respect to perceptions of risks and rewards.

Orla McBride is Reader in Psychology at the University of Ulster. She uses statistical models to analyse quantitative data from largescale general population health surveys and routinely collected administrative data.
Jamie Murphy is Professor of Psychology at the University of Ulster. His work investigates the expression of psychosis and the co-occurrence of psychological trauma and psychosis.

Mark Shevlin is Professor of Psychology at the University of Ulster. His research interests are in the areas of trauma, psychosis, and posttraumatic stress disorder.

Kate M. Bennett is Professor of Psychology at the University of Liverpool. Her work focuses on the psychology of later life including the interplay between physical and mental health and social relationships.

Philip Hyland is Senior Lecturer in Psychology at Maynooth University. His research focuses on measuring psychological responses to trauma, the psychosocial risk factors for different types of traumatic response, and the long-term outcomes of traumatic exposure.

Thanos Karatzias is Professor of Mental Health at Edinburgh Napier University. He has developed a special interest in the effects and treatment of psychological trauma on physical and mental health.

Frédérique Vallières is Assistant Professor in Global Health and Psychology at Trinity College Dublin. Her research is primarily concerned with closing the research-to-practice gap prevalent within global health.

Richard P. Bentall is Professor of Clinical Psychology at the University of Sheffield. His work focuses on social determinants and psychological mechanisms leading to symptoms of severe mental illness (hallucinations, delusions), as well as novel psychological treatments for people diagnosed with schizophrenia, bipolar disorder and other serious psychiatric disorders.

All authors are members of the COVID-19 Psychological Research Consortium, which aims to study the psychological, social, political, and economic impact of the COVID-19 pandemic on the general population.

Handling Editor: Danny Osborne 